\title{
PERFORMANCE MANAGEMENT SYSTEMS IN CZECH COMPANIES: FINDINGS FROM A QUESTIONNAIRE SURVEY
}

\author{
Michaela Stríteská, David Zapletal, Lucie Jelínková
}

\section{Introduction}

Increasing globalization and technological revolution represent the primary challenges for maintaining competitiveness in today's business environment. Concerning these challenges, businesses must create a longterm vision and formulate new strategies to allow managers to manage short-term performance in accordance with long-term needs. Therefore, measuring and managing performance is being increasingly emphasized. There are a growing number of companies that have realized that improving performance and increasing competitiveness can be achieved by developing effective performance measurement and management. However, increasing the implementation of performance measurement systems in companies is linked to many problems in need of answering.

Over the last 20 years, we have witnessed a revolution in the approach to measuring performance. In the context of a deeper understanding of this problematic, researchers and managers pose the question, "How can we best use the findings acquired by measuring performance for their management?" In relation to this, Maskel (1991) emphasizes changing the basis of performance measurement. The measures should be seen as part of fast feedback management systems and, at the same time, should be designed to stimulate continual improvement, rather than to merely monitor strategic operations. From this, it can be seen that identifying a relevant group of performance measures is only one aspect of performance management. If we accept this statement, it is possible to see a performance management system as Atkinson (2012) does, as a tool for interconnecting, improving and learning.

Shortcomings in current performance measurement, as shown by the research of
Stivers et al. (1998), are closely dependent on this. The first of these is that measures focused on innovation and employee engagement are not perceived to be as important as the measures of customer satisfaction and market share. The second is that managers realize the advantages and importance of using nonfinancial measures, although, naturally, a large number of companies still do not use these when measuring. The third shortcoming is that, though many companies acquire enough important information by measuring, managers do not use this information in the planning process. If we concede that intellectual capital is becoming the foundation for creating competitive advantage, it is necessary that the measures concerning innovation and employee engagement be a key part of the system. Unfortunately, more than fifteen years later, current research shows that these measures are still rarely used in current business practice (Střiteská \& Jelínková, 2015). Still, it is possible to state that many businesses put distinct effort into implementing measures that reflect all aspects of their performance. However, the focus is mainly on what should be measured today rather than what should be measured in the future (Kennerley \& Neely, 2003).

Effective performance management systems should also be based on system dynamics, sustainability and a simulated view of performance (Yadav et al., 2013). The concept of dynamics emphasizes that it is necessary to create a system that constantly monitors internal and external environments and consequently establishes and evaluates goals and priorities (Bititci \& Turner, 2002). The system's sustainability should be determined on the basis of stimulating continuous improvement of the measures and, subsequently, the performance management system processes. The dynamics of a performance management system can 
be ensured using tools or techniques such as cognitive maps, cause and effect diagrams, etc. (Yadav et al., 2013).

It is possible to see these features and shortcomings as future challenges for performance measurement and management - ones that require solutions. Research, however, always focuses more on performance measurement than on managing performance in a wider context (Neely, 2005). Kennerley and Neely (2003) state that few businesses have a set systematic process for managing the development of their performance measurement systems in a way that reflects organizational context. Furthermore, only few researchers have been dealing with the question, "What factors influence the development of a company's performance management system?"

Therefore, the main aim of this paper is to investigate the level of development of current performance management systems in Czech companies. The level of development is determined by fulfilment of the characteristics of an effective performance management system based on literature review. Attention is also paid to determination whether the level of a performance management system's development is dependent on company size.

\section{Literature Review}

According to Melnyk et al. (2014), the issue of performance measurement and management is composed of two elements: a performance measurement system and a performance management system. The performance measurement system encompasses the process (or processes) of establishing goals (developing a set of measures) and collecting, analyzing and interpreting data concerning performance. Even though measuring performance is important, it is not sufficient for managing a company on its own. Here, there is a complementary need for a performance management system that includes a process (or processes) for evaluating the differences between actual and desired results, identifying which of these differences are critical, understanding the origin of shortcomings and implementing correctional steps.

The performance measurement system thus becomes the core of the overall performance management system, supporting its philosophy and having fundamental significance for its effective and efficient operation (Lebas, 1995;
Bititci et al., 1997). Two basic functions are accomplished when managing a company's performance:

- facilitating communication between all the organizational units included in the process of target values,

- facilitating the collection, processing and provision of information concerning the performance of people, processes, products, services, activities, business units, etc.

An effectively functioning performance management and measurement system must meet a number of conditions. There are a number of authors in the literature that list these factors (Ghalayini \& Noble, 1996; Kennerley \& Neely, 2002; Bititci \& Turner, 2002, 2006; Ittner et al., 2003; Nita, 2008; Gomes et al., 2011). Using these authors' studies, it is possible to create the following summary of the characteristics they collectively recognize. The system must:

- ensure that there is a relationship between strategies, business activities and measurement of the results,

- provide a balanced view of performance and measure organizational abilities and the learning process,

- reflect non-financial aspects on the basis of the key factors for success; measures must be multidimensional, i.e., they must differentiate between measures focused on control and improvement,

- support an understanding of the causal relationships between measures,

- have measures that are incorporated across all hierarchical levels,

- be linked to a reward system,

- be dynamic and change in reaction to changes in the internal and external environment as well as in strategy.

Furthermore, the following aspects are also listed for what the performance measurement and management system must do:

- it must reflect the requirements of all stakeholders,

- it should stimulate a continual process of improvement,

- it must be understandable, clearly defined and viable.

The performance measurement and management system constitutes one integrated system, i.e., a system that must react in a timely way to changes in the exterior environment, strategy, organizational structure and company 
culture. In this context, it is necessary to realize that company strategy, structure and corporate culture determine how this integrated system reacts to these changes. Therefore, it is necessary to focus on the factors that can facilitate but simultaneously impede effective management of the development of the company's performance measurement system. These factors are pinpointed in a study conducted by Kennerley \& Neely (2003); the study was based on the analysis of seven case studies of businesses with at least one year's experience using a performance measurement system. The main key factors influencing the development of these systems were identified on the basis of interviews with managers:

- Corporate culture - the existence of a culture that ensures that performance measurement is not perceived negatively.

- People - access to the required knowledge and skills and their use, the ability to reflect company and employee needs, meeting requirements and implementing steps.

- Process - the existence of a process, its establishment, its review and the implementation of measures.

- Systems - the availability of flexible systems to facilitate collecting, analyzing and reporting the necessary data.

The same four key factors for successfully developing and implementing performance measurement and management systems are also identified by Atkinson (2012). Along with each group of these factors, he also lists concrete proposals for their development or reinforcement.

\section{Questionnaire Methodology}

First, it was necessary to establish research questions in order to achieve the main goal. The research questions concerned three basic areas:

1. Do current performance management systems correspond to the characteristics of effective measurement and management?

2. Do companies effectively manage the key factors influencing the development of the performance measurement system?

3. Is there an association between the level of development of an effective performance measurement and management system and company size?

Defined in this way, the research questions were developed into the form of a questionnaire.
The method of an electronic questionnaire was selected for acquiring data (Punch, 2008). The basic sample was comprised of enterprises from the five most competitive sectors in the Czech Republic; these were identified on the basis of the Czech TOP 100 list of companies for 2014 (see Fig. 1). For achieving the survey goals, two more criteria were set for selecting companies from the sectors listed above: 1) all companies actively conducting business in the Czech Republic with a turnover of CZK 30 million or more and 2) companies having over 50 employees. Namely, medium-sized and large companies were selected, because it can be assumed that they have a developed performance measurement system. Having been defined in this way, the basic sample was identified using the Magnus Web database. In the end, the basic sample included a total of 1,295 enterprises.

However, 51 questionnaires were not delivered to the respondents. The overall rate of return for questionnaires was $10.1 \%$, i.e., 126 companies. Formulas listed in Čermák (1980) were used to calculate sample size from the basic sample and the subsequent rate of return.

It is possible to describe the sample of companies that participated in the questionnaire using turnover, number of employees and type of ownership. The companies can be divided into two groups by turnover; $52 \%$ fall into the group of CZK 30-199.99 million, and 48\% have a turnover of CZK 200 million or more. The companies were divided into the following groups by number of employees: mediumsized enterprises with 50-250 employees (50\%), medium-sized to large companies with 251-500 employees (15\%) and those with 501 or more employees (35\%). According to type of ownership, the sample of businesses is comprised of companies with domestic ownership (53\%), companies partially or completely owned by international entities $(46 \%)$ and state-owned enterprises (1\%). Regarding the fact that the questionnaire was filled in anonymously, it is not possible to describe the respondents by sector.

\section{Statistical Methods}

Statistical software STATISTICA was used to calculate the statistics listed below. Pearson's $x^{2}$-test of independence was used to test the hypotheses concerning the random variable's independence. The testing criterion takes the form (Pacáková et al., 2009): 


\section{Fig. 1: The number of surveyed enterprises}

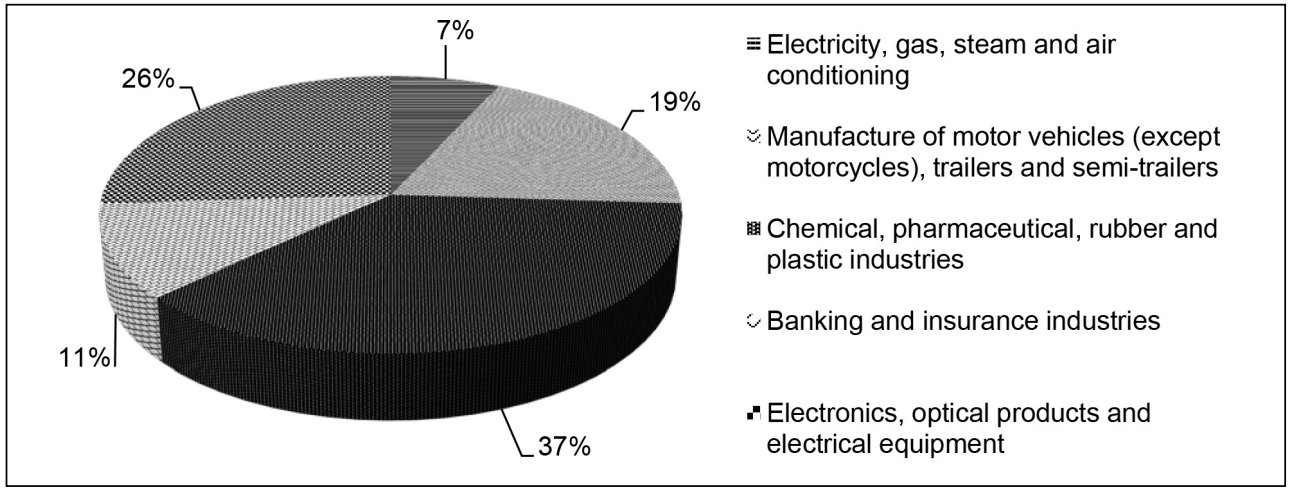

Source: own

$$
\chi^{2}=\sum_{j=1}^{S} \sum_{i=1}^{r} \frac{\left(O_{i j}-E_{i j}\right)^{2}}{E_{i j}}
$$

where

$r$ and $s$ are the numbers of permutations of the investigated categorical random variables, $O_{i j}$ are the observed frequencies and $E_{i j}$ denotes the theoretical frequencies.

The null hypothesis concerning independence of random variables is rejected if, for the given level of significance $\alpha$, it is true that:

$$
\chi^{2}>\chi_{1-\alpha}^{2}((r-1) \cdot(s-1))
$$

where $\chi_{1-\alpha}^{2}((r-1) \cdot(s-1))$ denotes $(1-\alpha)$ quantile of $x^{2}$-probability distribution with $(r-1)$. $(s-1)$ degrees of freedom. In that case, the $p$-value, which is provided by most of statistical software (including STATISTICA), is less than the level of significance $\alpha$.

For the assessment of the level of demonstrated dependence (association), Cramer's coefficient $V$ was used, which is given by the term

$$
V=\sqrt{\frac{\chi^{2}}{n \cdot h^{2}}}
$$

where $n$ is the overall number of units included in the sample and $h$ is the minimum of the numbers $(r-1)$ and $(s-1)$.

\section{Evaluation and Discussion}

First, attention was given to how long the performance measurement system has been implemented within the companies. The reason is that analysis of the level of the performance management system's development is better to perform in companies that have been focusing on this problematic over the long term. This prerequisite was met, because $60 \%$ of the companies have a performance measurement system implemented for longer than 5 years, $20 \%$ for three to five years and $10 \%$ for one to three years. Only $10 \%$ of the companies have a performance measurement system implemented for less than one year. Of the overall number of respondents, $21 \mathrm{did}$ not respond to this question.

The components comprising this system were determined for the companies being investigated in order to map the development of the current performance measurement systems. Otley (1999) considers a performance measurement system's main components to be goals, strategies, target values, reward systems and information flows (feedback and feed-forward). Using the literature review, it is possible to define these components in more detail: establishing a mission statement, vision, strategic objectives, performance measures and their target values; defining links between performance measures; cascading goals and measures down to the level of the individual; interconnection with the remuneration policy 
and strategy revision. Sixteen respondents did not reply to this question. Most of the companies have already defined the basic components used to develop strategic management, i.e., mission statement $(55 \%)$, vision $(66 \%)$, and strategic objectives $(87 \%)$. A large number of companies $(80 \%)$ have also defined performance measures and targets, which wish to achieve in the future. The research of Knápková et al. (2011) conducted in Czech companies found that, on average, $73 \%$ of companies base their performance measurements on their company strategies and objectives. Findings of our survey confirmed that there is constantly growing trend and that meeting with medium or large company in the practice who's PMS is not connected with strategy is a rarity.

Less than half $(45 \%)$ of the companies have cascaded strategic objectives and measures down to the individual level. An interesting finding is that $54 \%$ of the respondents stated that their performance measurement system is linked to their remuneration policy. This result is likely influenced by the fact that, for some respondents, a link to remuneration policy exists, though only at the strategic level, i.e., for top or middle management. Therefore, these respondents do not need to have strategic objectives cascaded down to the lowest hierarchical level. The performance measurement system components that the companies listed least frequently are defining logical relationships between performance measures (only $23 \%$ ) and strategy revision on the basis of performance measurement results $(30 \%)$.

The comprehensive performance measurement system defined by the authors contained nine components. The findings show that only $9 \%$ of the companies have a management process that is composed of all nine components, and $15 \%$ of the companies used 8 or 7 components. On the other hand, $22 \%$ of the companies have a management process comprised of less than four effective components. For most of the companies (42\%), their performance measurement system is composed of four or five components; $12 \%$ of the companies include six components.

The component analysis was subsequently used to divide the companies according to whether they met the seven basic characteristics of an effective performance measurement and management system. These characteristics were defined as follows on the basis of literature review. The performance measurement and management system must:

- have strategic objectives and measures derived from the mission statement or vision,

- be established as a tool for implementing strategy,

- set the targets of performance measures for what should be achieved during the projected period,

- support an understanding of causal relationships between measures,

- have performance measures integrated across the entire hierarchy and all functions,

- be linked to the reward system,

- change dynamically with the strategy and with changes in the internal and external environment.

Companies whose performance measurement and management system has 1-2 characteristics were classified as companies with a low level of development, companies with 3-5 characteristics were companies with an intermediate level of development and companies with 6-7 characteristics indicated a highly developed effective system. On the basis of this analysis, it is possible to state that $47 \%$ of the companies show a low level of development, $33 \%$ and intermediate level of development and $20 \%$ of the companies a high level of development for their performance management system.

Two of the characteristics listed above were investigated in more detail in the survey because they are problematic to implement in practice (Stríteská \& Jelínková, 2015). The first of these is the understanding of the causal relationships between objectives or measures. Therefore, it was determined how companies investigate the logical relationships between the performance measures that were used. In the previous question concerning the performance measurement system's components, it was determined that only $23 \%$ of the companies actually specify logical relationships. Of these companies, $68 \%$ define the relationships using strategic maps, and $32 \%$ describe them as part of each measure. Relating to this point, however, it is necessary to emphasize that $77 \%$ of the companies do not define logical relationships between objectives or measures. Sixteen respondents did not answer this question. It is 
truly surprising that such a high percentage of companies are not at all concerned with logical relationships, because research on causal modeling indicates that strategic maps can greatly simplify and facilitate communication within comprehensive systems (Fiol \& Huff, 1992; Forza \& Salvador, 2000; Vera-Muňoz, Shackell \& Buehmer, 2007; Stříteská \& Jelínková, 2015). According to recent research studies, it is necessary to increase the use of strategic maps, mapping tools, better representation of the system's causal structure (Barnabe, 2011) and diagramming tools such as causal loop diagrams and stock and flow diagrams when developing the performance measurement system (Yadav et al., 2012).

The British authors Bititci et al. (2002) state that one significant characteristic of an effective performance measurement and management system is to differentiate between control measures and improvement measures. However, this still proves to be problematic, because KPI are mostly lagging measures that reflect past performance. Furthermore, forwardlooking measures are often not integrated, nor do they sufficiently reflect the "soft" issues that determine future performance (Robinson et. al, 2005). On the basis of identifying this measurement gap, attention was given to the use of measures focused on control and improvement. For $62 \%$ of the companies, the performance measurement and management system contains both types of measures; $38 \%$ contain none. Unfortunately, this question was the one that the greatest number of respondents did not answer, i.e., 35. Subsequently, the proportion at which these measures were used was determined. The following results are derived from the answers of the respondents who were able to specify this proportion (Fig. 2). Of the companies, $42 \%$ use both measures categories at the same proportion; however, $44 \%$ of the companies still prefer result-oriented measures to improvement-oriented ones. Only $14 \%$ of the companies indicate the reverse and prefer to emphasize improvement measures.

The following question also concerned this problematic; specifically, it dealt with the importance of improvement-oriented measures. The question was whether the respondents perceived measures concerning innovation and employee engagement to have the same importance as, for example, measures concerning market position and the customer. Unfortunately, more than half, $57 \%$, of the companies prioritize the market and

\section{Fig. 2: Proportion of Measures in Performance Measurement System}

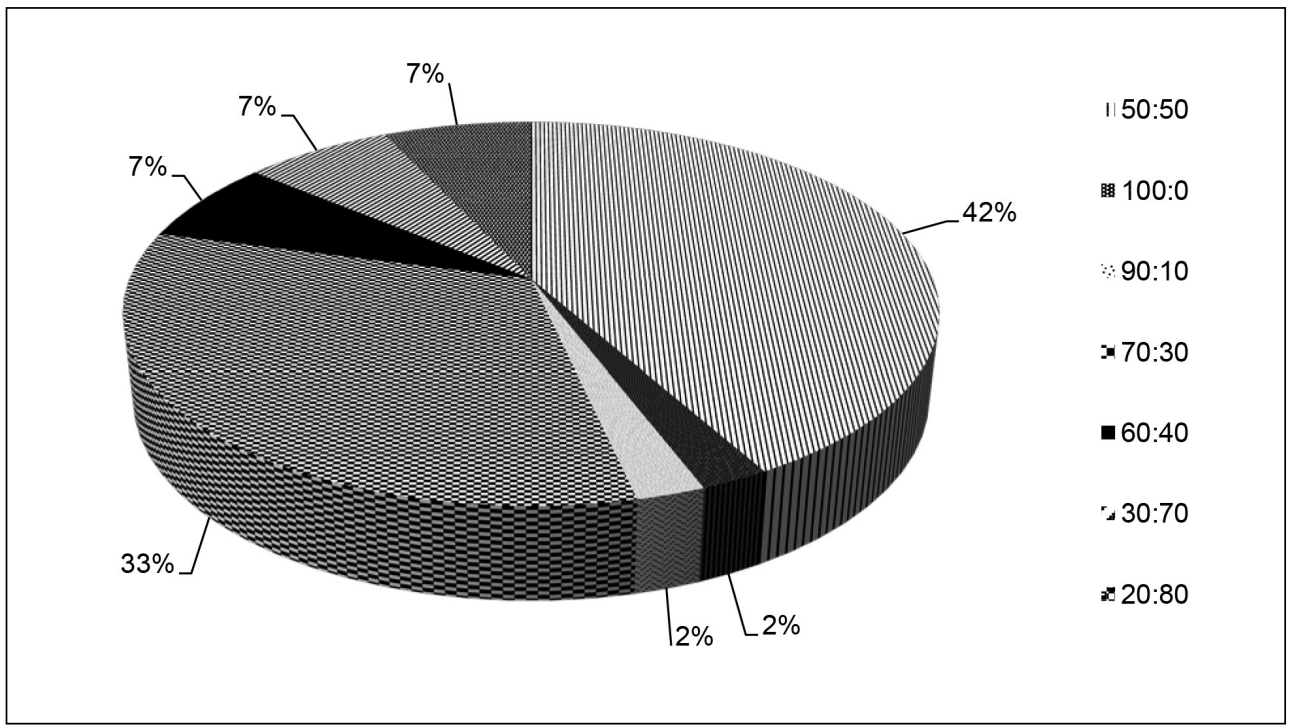


the customer above innovation and employee engagement, i.e., typical improvementoriented measures. $43 \%$ have the opposite perception of these measures and $68 \%$ from them listed specific examples of measures that are monitored in the company. The measures concerning innovation were primarily the number of innovations, the percentage of revenues from innovations, the effectiveness of using innovations and kaizen and quality circles. For employee engagement, the respondents most frequently listed the number of suggestions for improvement, the number of suggestions implemented and innovation competitions. This question was not answered by 18 respondents. The survey of Stivers et al. (1998) conducted in U.S. Fortune 500 and Canadian Post 300 companies revealed that customer service factors are perceived to be the most important measures by executives and factors in the innovation and employee involvement categories were perceived to be less important in goal setting. Almost twenty years later, the results of our survey are similar, despite the fact that intellectual capital and innovation are the foundation for maintaining competitive advantage.

The next set of questions was focused on factors influencing effective management of the performance measurement system. First, attention was given to corporate culture oriented on performance, improvement and learning. In a number of other studies, it was demonstrated that this factor plays the most significant role in implementing a performance management system (Stříteská \& Sadská, 2015). The greatest number of respondents stated that this type of corporate culture is created by the ability to learn from mistakes and adapt to a changing environment $(79 \%)$, $43 \%$ of companies use information acquired by performance measurement for reacting quickly and revising strategy and processes, $42 \%$ use visible commitment and support from top management and $32 \%$ use consistent communication and demonstration of the performance measurement and management system. From these results, it can be seen that communication is still an undervalued aspect when creating a performance-oriented culture; therefore, we frequently witness failure to implement a performance measurement and management system. Atkinson (2012) states that communication, concerning progress and benefits, is one of the most important means to successful implementation. To summarize we can state that only $13 \%$ of the respondents check all four aspects of performance-oriented company culture. However, $42 \%$ of the respondents utilize only one of the aspects of performance-oriented culture that were mentioned. Of the respondents, $31 \%$ utilize two of the aspects mentioned, and $14 \%$ utilize three. This question was not answered by 15 respondents.

Another factor that also closely relates to performance-oriented company culture is people. Primarily, this means whether employees have the competence to change how the performance measurement system is configured and, if the answer is yes, whether they have access to suitable tools. Of the companies, $69 \%$ stated that they are able to change the performance measurement system; $31 \%$ do not have this competence. Of those that have the authority to change the system, $79 \%$ have suitable tools. This fact is very positive and relates to the previous factor of performance-oriented company culture because the ability to learn from mistakes and adapt to a changing environment is the thing that most frequently creates such a culture for the companies investigated. However, it is also necessary to further research the question of whether employees have the necessary knowledge and skills to enact such change.

The third factor that was investigated is the existence and quality of the process for reviewing, modifying and implementing performance measures. Unfortunately, $60 \%$ of the respondents were unable to answer this question. Still, it is possible to conclude from this that engaging this factor is distinctly problematic in practice. Of the respondents, $40 \%$ tried to characterize the process of reviewing performance measures, but only $5 \%$ were able to describe the individual steps of this process clearly. The other respondents described this process very briefly or incompletely; it is not possible to consider them to be companies that manage this process effectively. The respondents review the measures once a year at most.

The last factor dealt with in the questionnaire is the existence of information systems used for collecting, analyzing and reporting the acquired data. As stated Myšková (2011) implementation of information system in a company is 
a result of major decision-making of company management, because it projects to a number of corporate activities. Even in decision-making phase there are a number of alternatives; this problem includes economic and technical viewpoints. Synergy effect can be reached only if requirements in both areas are fulfilled optimally. The primary factor evaluated was flexibility, i.e., the thing that makes it possible to easily alter these activities. Of the respondents, $87 \%$ consider the information systems used in their companies to be flexible; only $13 \%$ do not. Those who consider them to be inflexible do not consider the overall performance measurement system to be flexible, because it is managed centrally and is a global tool that does not allow for adapting evaluation to a specific location. This question was not answered by 19 respondents.

The questions listed above that concerned the key factors influencing an effective performance measurement and management system were also evaluated collectively, i.e., the overall number of factors utilized by the companies. This analysis excluded the 19 respondents who did not answer all the questions. In conclusion, it was determined that only $12 \%$ of the companies manage all four factors, and $25 \%$ manage three factors. Thus, this included only a little over a third of the companies. The greatest number of respondents utilizes two factors $(32 \%)$ or only one factor (31\%).

The last research question was focused on investigating the variables influencing the level of development of an effective performance measurement and management system. Because the problem is wide-reaching, only one variable, company size, will be dealt with here. Knápková, Homolka and Pavelková (2014) in research conducted in Czech companies dealing with the fact that the use of Balanced Scorecard concept depends on the company size. The results demonstrated this dependency. Based on this finding, we decided to deepen the research in this area and further examine whether the level of development of an effective performance management system linked to the company size.

The first step is to establish the null and the alternative hypothesis to be tested.

$H_{0}$ : The level of development of an effective performance measurement and management system is not dependent on company size.

\section{Tab. 1: The observed frequencies $O_{i j}$}

\begin{tabular}{l|r|r|r|r}
\multirow{2}{*}{ Size of a company } & \multicolumn{5}{|c}{ Level of development of e. p. m. s. } \\
\cline { 2 - 6 } & \multicolumn{1}{|c|}{ Low level } & \multicolumn{1}{c}{ Intermediate level } & \multicolumn{1}{c}{ High level } & \multicolumn{1}{c}{ Total } \\
\hline Medium-sized & 38 & 14 & 3 & $\mathbf{5 5}$ \\
\hline Medium-sized to large & 7 & 7 & 3 & $\mathbf{1 7}$ \\
\hline Large & 7 & 15 & 16 & $\mathbf{3 8}$ \\
\hline Total & $\mathbf{5 2}$ & $\mathbf{3 6}$ & $\mathbf{2 2}$ & $\mathbf{1 1 0}$ \\
\hline
\end{tabular}

\section{Tab. 2: The expected frequencies $E_{i j}$}

\begin{tabular}{l|r|r|r|r}
\multirow{2}{*}{\multicolumn{1}{c|}{ Size of a company }} & \multicolumn{4}{c}{ Level of development of e. p. m. s. } \\
\cline { 2 - 5 } & Low level & Intermediate level & High level & Total \\
\hline Medium-sized & 26.000 & 18.000 & 11.000 & $\mathbf{5 5}$ \\
\hline Medium-sized to large & 8.036 & 5.564 & 3.400 & $\mathbf{1 7}$ \\
\hline Large & 17.964 & 12.436 & 7.600 & $\mathbf{3 8}$ \\
\hline Total & $\mathbf{5 2}$ & $\mathbf{3 6}$ & $\mathbf{2 2}$ & $\mathbf{1 1 0}$ \\
\hline
\end{tabular}


$H_{A}$ : The level of development of an effective performance measurement and management system is dependent on company size.

For testing this hypothesis the companies were divided on the basis of two criteria: the level of development of an effective performance measurement and management system (low, intermediate and high) and company size (medium, medium to large, large), see Tab. 1.

For impendence testing was used above mentioned Pearson's $x^{2}$-test of independence. That is why expected frequencies were calculated (Tab. 2).

The value of the tested criteria for Pearson's $x^{2}$-test is, in this case, $x^{2}=29.301$ and the corresponding $p$-value essentially equals zero, which unequivocally proves the rejection of the null hypothesis $H_{0}$ in favor of the alternative $H_{A}$. We can thus state that the level of development of an effective performance management system is dependent on company size.

Cramér's coefficient $V$ is equal to 0.365 , which indicates moderate dependence (association).

\section{Conclusion}

The basis for managing performance has changed in recent years. It is necessary to see performance management as a systematic process that has a performance measurement system reflecting the wider organizational context at its core. In order for performance management to work effectively in a company, the literature states that a number of characteristics must be met. On the basis of meeting these characteristics we divided the companies examined into three categories. The findings show that $47 \%$ of the companies have a low level of development, $33 \%$ and intermediate level of development and $20 \%$ of the companies a high level of development for their performance management system. The reason is that use of certain of these characteristics proves to be very problematic in practice.

Firstly, the current performance measurement systems at the companies do not contain the components of logical relationships between performance measures and strategy revision. Thus, they do not meet the characteristics of an effective performance management system, because they do not support an understanding of causal relationships, and they do not change dynamically with the strategy. Two other components that also remain problematic are hierarchical and cross-functional linkages of objectives and performance measures and taking into account motivational aspects.

Secondly, the use of leading measures to facilitate a more proactive performance management style is still not evenhanded. Almost $60 \%$ of the companies still prioritize measures relating to the market and customers above innovations and employee engagement, which are considered typical improvementoriented measures. It is thus necessary to strongly reinforce the role of measures relating to leadership, employee education, innovation, skills, knowledge and personal development in the current performance measurement systems.

Thirdly, the research conducted here revealed that only $12 \%$ of the companies manage all four factors that facilitate or impede the successful development of a performance management system and are closely linked to its effectiveness. The essentially nonutilized factor is the existence and quality of the process for reviewing, modifying and implementing performance measures within the performance measurement system. Only $5 \%$ of the companies, which is a truly negligible percentage, were able to clearly define the individual steps of this process. The question is whether this result could have been influenced by the position held by the respondents answering the questionnaire and their knowledge of the problematic. Seeing that the questionnaire was sent to individual department managers or general directors, it is possible to presume instead that this process is, in fact, not clearly established in the company.

Another interesting finding is that it is still difficult for companies to manage the factor of performance-oriented company culture. Mainly consistent communication and demonstration of the performance measuring system's benefits is the most undervalued aspect of utilizing this factor. Seeing that utilizing the factors of company culture and process is problematic for most of the companies, their systems are thus unable to change dynamically along with strategy. On the other hand, the fact that the other two factors - people and systems - are largely engaged by the companies can be considered a positive finding. 
In conclusion, the hypothesis that the level of development of an effective performance measurement and management system is not dependent on company size was also tested. On the basis of the statistical calculations that were conducted, this hypothesis was rejected, and it is possible to state that the level of development of an effective performance management system is dependent on company size.

This article was created with the support of SGSFES_2015001 project.

\section{References}

Atkinson, M. (2012). Developing and Using a Performance Management Framework: A Case Study. Measuring business excellence, 16(3), 47-56. doi:10.1108/13683041211257402.

Barnabe, F. (2011).ASystem Dynamics-Based BalancedScorecard toSupportStrategic Decision Making. International Journal of Productivity and Performance Management, 60(5), 446473. doi: $10.1108 / 17410401111140383$.

Bititci, U. S., Carrie, A. S., \& McDevitt, L. (1997). Integrated Performance Measurement Systems: a Development Guide. International Journal of Operations \& Production Management, 17(5/6), 522-534. doi:10.1108/01443579710167230.

Bititci, U. S., Carrie, A., \& Turner, T. (2002). Integrated Performance Measurement Systems: Structure and Dynamics. In A. Neely (Ed.), Business Performance Measurement: Theory and Practice (pp. 174-197). Cambridge: Cambridge University Press. doi:10.1017/ CBO9780511753695.012.

Bititci, U., Carrie, A., \& Turner, T. (2006). Integrated Performance Measurement Systems: Structure and Dynamics. Business Performance Measurement. Theory and Practice. Cambridge, Cambridge University Press.

CZECHTOP100. (2014). RESULTS of 100 Most Significant Companies in the Czech Republic. Retrieved November 11, 2014, from http://www.czechtop100.cz/menu/ aktualne/100-nejvyznmanejsich-firem-cr.html.

Čermák, V. (1980). Výběrové statistické zjištování. Praha: SNTL/Bratislava: Alfa.

Fiol, C. M., \& Huff, A. S. (1992). Maps for Managers: Where are we? Where do we go from here? Journal of Management Studies. 29(3), 267-285. doi:10.1111/j.1467-6486.1992. tb00665.x.
Forza, C., \& Salvador, F. (2000). Assessing some Distinctive Dimensions of Performance Feedback Information in High Performing Plants. International Journal of Operations \& Production Management, 20(3), 359-385. doi:10.1108/01443570010308112.

Ghalayini, A. M., \& Noble, J. S. (1996). The Changing Basis of Performance Measurement. International Journal of Operations \& Production Management, 16(8), 63-80. doi:10.1108/01443579610125787.

Gomes, C. F., Yasin, M. M., \& Lisboa, J. V. (2011) Performance Measurement Practices in Manufacturing Firms Revisited. International Journal of Operations and Production Management, 31(1), 5-30. doi:10.1108/01443571111098726.

Ittner, C., Larcker, D., \& Randall, T. (2003) Performance Implications of Strategic Performance Measurement in Financial Service Firms. Accounting, Organizations and Society, 28(7/8), 715-741. doi:10.1016/S03613682(03)00033-3.

Kennerley, M., \& Neely, A. (2002). A Framework of the Factors Affecting the Evolution of Performance Measurement System. International Journal of Operations and Production Management, 22(11), 1222-1245. doi:10.1108/01443570210450293.

Kennerley, M., \& Neely, A. (2003). Measuring Performance in a Changing Business Environment. International Journal of Operations and Production Management, 23(2), 213-229. doi:10.1108/0144370310458465.

Knápková, A., Homolka, L., \& Gavurová, B. (2014). Využití Balanced Scorecard a vliv jeho využívání na finační výkonnost podniků v ČR. E\&M Ekonomie a Management, 17(2), 146160. doi:10.15240/tul/001/2014-2-011.

Knápková, A., Pavelková, D., \& Chodur, M. (2011). Měření a řízení výkonnosti podniku. Praha: Linde.

Lebas, M. J. (1995). Performance Measurement and Performance Management. International Journal of Production Economics, 41(1/3), 23-35. doi:10.1016/09255273(95)00081-X.

Maskel, B. H. (1991). Performance Measurement for World Class Manufacturing: A Model for American Companies. New York: Productivity Press.

Melnyk, A., Bititci, U., Platts, K., Tobias J., \& Andersen, B. (2014). Is Performance Measurement and Management Fit for the 
Future? Management Accounting Research, 25(2), 173-186. doi:10.1016/j.mar.2013.07.007.

Myšková, R. (2011). Economic Information Systems for Small and Medium Businesses and Evaluation of Return. Wseas Transaction on Information Science and Applications, 8(3), 119-128.

Neely, A. (2005). The Evolution of Performance Measurement Research: Development in the Last Decade and a Research Agenda for the Next. International Journal of Operation \& Production Management, 17(11), 1131-1152. doi:10.1108/01443570510633648.

Nita, B. (2008). Requirements for Performance Management Systems: A Delineation of the Comprehensive Set of Criteria. European Financial and Accounting Journal, 3(3), 6-22.

Otley, D. T. (1999). Performance Management: A Framework for Management Control Systems Research. Management Accounting Research, 10(4), 363-382. doi:10.1006/mare.1999.0115.

Pacáková, V. et al. (2009). Štatistické metódy pre ekonómov. Bratislava: lura Edition.

Punch, K. F. (2008). Základy kvantitativního šetření. Praha: Portál.

Robinson, H. S., Carrillo, P. M., Anumba, C. J., \& Al-Ghassani, A. M. (2005). Review and Implementation of Performance Management Models in Construction Engineering Organizations. Construction Innovation, 5(4), 203-217. doi:10.1108/14714170510815258.

Stivers, B. P., Covin, T. J., Hall, N. G., \& Smalt, S. W. (1998) How Nonfinancial Performance Measures Are Used. Management Accounting, 44(February), 46-49.

Stříteská, M., \& Jelínková, L. (2015). Trends in Performance Management: Comparison and Summary of Surveys. In Finance and Performance of firms in Science, Education and Practice. April 23 - 24, 2015. (pp. 1443-1479).

Stríteská, M., \& Jelínková, L. (2015). The Characteristics of Effective Performance Measurement System: Case Study Analysis. In Proceedings of Energy, Environment, Development and Economics. Conferences of INASE.org, Zakynthos, Greece, July 16-20, 2015 (7 p.).
Střiteská, M., \& Sadská, V. (2015). A case Study of Performance Management System Implementation. Innovation Management and Sustainable Economic Competitive Advantage: From Regional Development to Global Growth. In Proceedings of 26th International Business Information Management Association Conference. November 11-12, 2015, Madrid, Spain (pp. 1561-1568).

Yadav, N., Sushil, \& Sagar, M. (2012). Dynamics of Strategic Initiatives and Expected Performance: An Application of Flexible Strategy Game-card. In Proceedings of $30^{\text {th }}$ International conference of System Dynamics Society, University of St. Gallen, March 16, 2012.

Yadav, N., Sushil, \& Sagar, M. (2013). Performance Measurement and Management Frameworks: Research Trends of the Last Two Decades. Business Process Management Journal, 19(6), 947-970. doi:10.1108/BPMJ-012013-0003.

Vera-Muňoz, S. C., Shackell, M., \& Buehmer, M. (2007). Accountants' Usage of Causal Business Models in the Presence of Benchmark Data: A Note. Contemporary Accounting Research, 24(3), 1015-1038. doi:10.1506/car.24.3.12.

Ing. Michaela Střiteská, Ph.D. University of Pardubice

Faculty of Economics and Administration Institute of Business Economy and Management michaela.striteska@upce.cz

Mgr. David Zapletal, Ph.D. University of Pardubice

Faculty of Economics and Administration Institute of Mathematics and Quantitative Methods david.zapletal@upce.cz

Ing. Lucie Jelínková

University of Pardubice

Faculty of Economics and Administration Institute of Business Economy and Management lucie.jelinkova@upce.cz 


\title{
PERFORMANCE MANAGEMENT SYSTEMS IN CZECH COMPANIES: FINDINGS FROM A QUESTIONNAIRE SURVEY
}

\author{
Michaela Stříteská, David Zapletal, Lucie Jelínková
}

Measuring and managing performance is an integral part of contemporary management systems, which are focused on achieving outstanding business results. This is based on a systematic, comprehensive review of a company's activities and results with the goal of identifying weaknesses and opportunities for improvement.

Therefore, it is put more emphasis on the development of an effective performance measurement and management system as a tool for enhancing business competitiveness. Given the importance and urgency of this issue the revolutionary developments in this area can be observed over the last 20 years. Researchers and managers are constantly trying to understand all the variables affecting the performance of the company. They are looking for an answer to the question of how best to use the lessons learned from performance measurement to its management. They design and develop various concepts, frameworks and methods for measuring and managing performance in the current business practice. They are constantly trying to eliminate the drawbacks of contemporary systems in order to increase their effectiveness. Cognition of these systems, their characteristics and identification of weaknesses can be seen as challenges for performance measurement and management in the future, for which solutions must be found.

Therefore, the primary goal of this paper is to investigate the level of development of current performance management systems in Czech companies. The level of development is determined by fulfilment of the characteristics of an effective performance management system based on literature review. Attention is also paid to determination whether the level of a performance management system's development is dependent on company size. The method of an electronic questionnaire was selected for acquiring data.

Key Words: Performance, measurement, management, system.

JEL Classification: M14, M21, M29.

DOI: 10.15240/tul/001/2016-4-004 